\title{
Impacto y consecuencias del viaje a los Estados Unidos de 1945 en el ministerio de san Alberto Hurtado ${ }^{1}$
}

\author{
Mariana Clavero \\ CENTRO DE ESTUDIOS SAN ALBERTO HURTADO \\ FACULTAD DE TEOLOGÍA \\ PONTIFICIA UNIVERSIDAD CATÓLICA DE CHILE
}

«Vengo llegando del país más grande del mundo.

$Y$ ¿qué impresión de conjunto?

Que la materia no basta, que la civilización no llena...

¿Que da demasiado poco y cobra demasiado caro!»

(A. Hurtado, de regreso de su viaje a los EE. UU.)

\section{Introducción}

En octubre de 1944, después del encuentro con el mendigo, Alberto Hurtado fundó el Hogar de Cristo $^{2}$. En diciembre del mismo año, por razones de otra índole, debió presentar la renuncia a su cargo de Asesor Nacional de la Rama de Jóvenes de la Acción Católica ${ }^{3}$. Casi inmediatamente después, en enero de 1945, impactado por el encuentro con el mendigo, comenzó a escribir «un libro sobre nuestro deber social, educación social, vida sociali ${ }^{4}$, cuyo título original sería Vida social y deberes sociales ${ }^{5}$.

1 Este trabajo forma parte del desarrollo del Proyecto Fondecyt 1090033 (año 2009): Evolución cronológica del pensamiento y de la acción de Alberto Hurtado entre 1936 y 1952.

2 Cf. S. Fernández, «Circunstancias de la fundación del Hogar de Cristo. Estudio histórico en los documentos contemporáneos», en Teología y Vida, IL (2008) 875-891.

3 Cf. J. Castellón (ed.), Cartas e informes del Padre Alberto Hurtado, S.J. (Santiago, 2003) 115-139.

4 J. Castellón (ed.), Cartas e informes, 203.

5 Se conservan dos manuscritos que dan cuenta de la redacción de este libro en el verano de 1945: Vida socialy deberes sociales (APH s24y01a), y Nuestro deber social (APH s24y01b). $A P H=$ Archivo Padre Hurtado, sobre y número del documento. 
Esto muestra a Alberto Hurtado como un santo estudioso ${ }^{6}$, que valoraba la reflexión, pues justo después de fundar el Hogar de Cristo, en vez de volcarse inmediatamente a la acción, comenzó a redactar un libro con «indicaciones básicas de lo que constituye una "actitud" católica, un "estilo" de vida católico frente al problema sociabi ${ }^{7}$. Pero no concluyó este libro, sino hasta dos años después ${ }^{8}$. ¿Qué sucedió entremedio? Posiblemente, al comenzar la redacción de este libro, debió sentir la necesidad de estudiar más a fondo la «actitud católica» frente al problema social. Esto lo debió impulsar a aceptar la invitación de Mons. O’Hara, que visitó Chile en abril de 1945, para estudiar por un año en la Escuela de Trabajo Social de la Universidad Católica de Washington, para profundizar el estudio del Magisterio Social de la Iglesia. Paradójicamente, al regresar de EE. UU., en su primera predicación pública, el retiro a jóvenes de Semana Santa de 1946, no se destacan los temas sociales, sino los espirituales y existenciales. Este contrastante itinerario impulsa a preguntarse: ¿qué significó el viaje a EE. UU. para el ministerio de Alberto Hurtado? El presente artículo busca responder esta pregunta. Normalmente, se ha señalado que Alberto Hurtado realizó este viaje con «el fin de renovarse» después de su dolorosa salida de la Acción Católica ${ }^{9}$, pero las fuentes permiten ir más allá.

$\mathrm{El}$ presente estudio se divide en dos partes. La primera presenta una descripción cronológica del viaje. Y la segunda, pretende mostrar sistemáticamente cuáles fueron los elementos esenciales que Alberto Hurtado aprendió en Norteamérica y que marcaron su apostolado en Chile. Con este propósito, han sido estudiados los documentos del archivo digital del Centro de Estudios San Alberto Hurtado, al que han sido agregados recien-

6 Cf. J. Ochagavía, «Padre Alberto Hurtado. Un Santo estudioso», Mensaje, 543 (2005) 38-44; J. Ochagavía, «Santidad y Teología. Reflexiones en la canonización del padre Hurtado», Teología y Vida, XLVI (2005) 427-438; S. FernándeZ, «Relación del Padre Alberto Hurtado S.J., con la Facultad de Teología de la Pontificia Universidad Católica de Chile», Teología y Vida, XLIV (2003) 3-18; S. FERnÁndeZ, «Correspondencia del Padre Alberto Hurtado C., S.J., relacionada con la fundación de la Facultad de Teología de la Pontificia Universidad Católica de Chile», Teología y Vida, XLIV (2003) 19-47 y J. Costadoat, «Pietas et eruditio en Alberto Hurtado, S.J.», Teología y Vida, XLVI (2005) 321-352.

7 Nuestro deber social, [1945], APH s24y01b. Al analizar el manuscrito, queda claro que se trata de la introducción del libro que se había propuesto escribir en este tiempo.

8 Este proyecto concluyó, en 1947, con la publicación de Humanismo Social.

9 J. Castellón, Padre Alberto Hurtado S.J. Su espiritualidad (Santiago 1998) 95. 
temente algunas cartas de Mons. Edwin O’Hara, que permiten conocer mejor este período.

\section{Descripción cronológica del viaje}

\section{La invitación}

El 21 de abril de 1945 llegó a Chile Mons. Edwin O’Hara, obispo de Kansas City, invitado por la Acción Católica ${ }^{10}$. En su estadía en Chile, debió conocer al padre Hurtado y debió quedar muy bien impresionado, puesto que rápidamente le ofreció una beca consistente en un año de estudio en la Escuela de Trabajo Social de la Universidad Católica de Washington ${ }^{11}$. De hecho, sabemos que a las pocas semanas de haber visitado nuestro país, el propio obispo de Kansas le escribe en dos ocasiones para concretar la invitación, el 4 y el 21 de junio de 1945, lo que demuestra el interés del obispo ${ }^{12}$. O’Hara ofrecía becas a un grupo selecto de sacerdotes latinoamericanos y quería contar con Alberto Hurtado. Así lo demuestra una tercera carta, del 7 de agosto, donde le dice que «no quieren quedarse sin un representante de Chiles $^{13}$.

Alberto Hurtado responde el 28 de julio a la invitación, agradeciéndole la beca que Su Excelencia amablemente le ha otorgado y comprometiéndose a hacer todo lo posible para llenar sus expectativas. Solo que no podrá llegar hasta fines de septiembre, por su trabajo en la Universidad Católica de Chile ${ }^{14}$.

10 Cf. El Diario Ilustrado, 21 abril de 1945; El Mercurio de Santiago, 21 abril de 1945.

11 Así se deduce de una carta de O’Hara al P. Wilfred Parsons: «I have a donor who has given the full scholarships for a year at the Catholic University to these Latin American priests» (Archivo de Monseñor Edwin O'Hara). No queda claro si la beca le fue ofrecida directamente por Mons. O’Hara durante su estadía en Chile, en abril de 1945, o algunas semanas después por medio del P. Weigel (cf. Carta a Edwin O'Hara, 1945, $A P H$ s70y131). El hecho es que el obispo de Kansas City muestra un fuerte interés por contar con el padre Hurtado entre los becados.

12 Estas cartas no se conservan, pero el padre Hurtado alude a ellas en su respuesta a Mons. O’Hara del 28 de julio de 1945 (cf. Carta a Edwin O'Hara, 1945, APH s70y131).

13 Carta de Edwin O'Hara, 1945, CR1945m08d07 (CR = Carta recibida, seguido por la indicación de la fecha. Estas cartas se conservan en el Archivo Padre Hurtado).

14 Cf. Carta a Edwin O'Hara, 1945, APH s70y131. 


\section{El viaje}

El 16 de septiembre de 1945 inicia su viaje. En el trayecto, se detiene en Antofagasta, Arequipa, Lima, Panamá, San José de Costa Rica, y Ciudad de Méjico ${ }^{15}$. Aprovecha, como de costumbre, de entrevistarse con personalidades de estos países, interesándose especialmente por Mons. Sanabria y su labor social en Costa Rica, y por el partido político «los cristeros» de Méjico $^{16}$. Permanece en Ciudad de Méjico desde el 22 de septiembre hasta el 4 de octubre. Visita comunidades de religiosos, la oficina de la Acción Católica y queda sumamente impresionado por la fe de los mejicanos: «La persecución afian₹ó mucho la fe» ${ }^{17}$. Visita la Basílica de Nuestra Señora de Guadalupe, donde celebra la misa, señalando luego que: «El amor de los Mejicanos por la Virgen de Guadalupe es algo único en el mundo». Finalmente, el 4 de octubre deja Ciudad de Méjico y parte rumbo a Kansas City ${ }^{18}$.

\section{Estadía en Kansas}

El 5 de octubre, una vez llegado a Kansas, el padre Hurtado es conducido por el obispo, quien lo lleva «manejando él su coche», a visitar algunas comunidades religiosas, la Cancillería y la oficina de la Acción Católica ${ }^{19}$. Comienza entonces un intenso recorrido por las diversas obras sociales de la diócesis, buscando ideas para el Hogar de Cristo. En este recorrido, aprovecha de aprender lo más posible: toma notas, pregunta, se entrevista con muchas personas involucradas en temas sociales, asiste a conferencias, etc. Entre las obras de caridad que visita, están la famosa Ciudad del Niño del P. O'Flanagan ${ }^{20}$, una hospedería fundada por el P. Trin en St. Louis $^{21}$, la hospedería para vagos de la Catedral de Kansas, Saint Christopher's Inn, y varias obras conducidas por religiosas. Pasa unos días en St. Louis

15 Cf. [Diario de viaje a EE. UU. I], 1945, APH s16y01; [Diario de viaje a EE. UU. III], 1945, APH s16y06 y Méjico, [1945], APH s29y12. La visa registra el propósito del viaje: «Trabajo de estudio social con beca otorgada por el Obispo de Kansas City, Rev. Edwin O'Hara».

16 En Costa Rica, junto con Mons. Sanabria, le atrae mucho el trabajo del P. Núñez, Presidente del Sindicalismo de ese país. Junto a él va a sacar a un carretelero tomado preso, cf. [Diario de viaje a EE. UU. I], 1945, APH s16y01.

17 Méjico, [1945], APH s29y12.

18 Cf. Carta a Rebeca de Franke, 1945, APH s65y38.

19 Cf. Kansas City, 1945, APH s16y08.

20 Cf. Carta a Rebeca de Franke, 1945, APH s65y38.

21 Cf. Carta a Mercedes Peña, 1945, APH s65y05. 
por consejo del padre Mac Donald a visitar los hoteles para pobres del padre Demsey. Además, toma muchas notas de la labor del P. Murphy, a cargo de una radio, y del Queen's Work, la Central de las Congregaciones Marianas dirigida por el P. Lord 22 .

Alberto Hurtado permanece hasta fines de octubre en la diócesis de Mons. O’Hara, en la residencia de jesuitas de la Universidad de Rockhurst. Su propósito era conocer lo más posible las obras de la Iglesia estadounidense, particularmente en temas sociales y educacionales ${ }^{23}$, y Edwin O'Hara no era ajeno a estos temas: impulsor de la institución The Rural Life, dedicada al problema campesino y Presidente de la Confraternity of Christian Doctrine, dedicada a la enseñanza religiosa. Además en la Catedral de su diócesis, funcionaba una de las más grandes hospederías para vagos del país.

Alberto Hurtado se interesa especialmente por el trabajo del Rockhurst Institute, de los jesuitas de Kansas ${ }^{24}$, y por la organización The Rural Life, impulsada por el mismo O'Hara. Viaja a Des Moines (Iowa), para asisitir a un Congreso de esta organización de desarrollo rural ${ }^{25}$, y a Nebraska (Omaha), para escuchar una conferencia de John Clerk, el decano de la Facultad de Comercio de la Universidad de Nebraska, ante hombres de negocios $^{26}$. Pasa por Sheboygan (Wisconsin), para entrevistarse con el P. Bede Friedrich, Provincial de los Salvatorianos, para proponerle un proyecto de escuela agrícola en Chile ${ }^{27}$.

\section{Estudios en Washington y viaje a Canadá}

El 29 de octubre ya se encuentra en Washington (se aloja en la residencia de jesuitas de la Universidad de Georgetown) para iniciar sus estudios en la Escuela de Trabajo Social de la Universidad Católica de Washington.

22 St. Christopher's Inn, [1945], APH s16y09.

23 Cf. Carta de Edwin O’Hara a Thomas Mitchell, del 25 de septiembre de 1945: «The five who have arrived have made good use of the month or six weeks they have been with us in improving their English and in getting acquainted with parish life and American conditions generally» (cf. Archivo de Monseñor Edwin O’Hara).

24 Cf. The Road of Serfdom in Europe, 1945, APH s16y10 y The San Antonio plan, [1945], APH s15y06.

25 Cf. Rural Life Conference, [1945], APH s15y09 y [Encuentro Nacional de Rural Life], [1945], APH s15y05.

26 Cf. Dr. John Clerk, 1945, APH s16y11.

27 Cf. Carta de Bede Friedrich, 1945, CR1945m10d29. 
Toma cursos sobre Filosofía y Religión, con Mons. Fulton Sheen ${ }^{28}$ y «Cristocentrismo en la enseñanza de la Religión», con el padre W.H. Russell ${ }^{29}$, orientados al estudio de la enseñanza religiosa. Además de las clases en la Universidad, toma un curso de Sociología con el padre McGowan en la National Catholic Welfare Conference ${ }^{30}$, institución de los obispos de EE. UU. dedicada a estudiar políticas de educación, imigración y acción social.

Posiblemente en noviembre, participa en tres Seminarios de Sociología y de una reunión de Pax Romana en Nueva York ${ }^{31}$. Durante todo este tiempo se mantiene muy bien informado de lo que pasa en Chile, especialmente con el naciente Hogar de Cristo $^{32}$.

A comienzos de diciembre, Alberto Hurtado le escribe a Mons. O’Hara, dándole noticias de su vida en Washington. Le confiesa que ha llevado una vida normal de estudiante, trabajando con las encíclicas y pastorales sociales, «para encontrar en sus fuentes el pensamiento católico social tal como es concebido por la Jerarquía ${ }^{33}$. Le explica que su propósito es ordenar los documentos papales de acuerdo con los principales problemos sociológicos ${ }^{34}$. En la misma carta, le cuenta haber visitado los Ministerios de Agricultura y de Educación, para conocer lo que el Gobierno está haciendo en temas de desarrollo rural. Por último, le expone sus planes de ir a Canadá, durante las vacaciones de Navidad, para estudiar la Acción Católica, la Juventud Obrera Católica (JOC), la Liga Obrera Católica (LOC) y las cooperativas,

28 Se conservan algunas de sus notas: The philosophy of comparatives religions, [1945], APH s15y10; The grammar of assent, [1945], APH s15y11 y Causas de escepticismo, [1945], APH s15y12.

29 CClase con el P. Russell], [1945], APH s15y01; Cristocentrismo en la enseñanza de la Religión, [1945], APH s68y15 y Esquema de Cristocentrismo, [1945], APH s61y08b.

30 Estados Unidos, [1946], APH s16y03 y Padre Higgins, [1945], APH s60y02. La NCWC había sido fundada en 1919 con el propósito de formular reformas en educación, imigración y acción social, y mantuvo su unidad hasta que fue reemplazada por la Conferencia Nacional de Obispos Católicos en 1966, cumpliendo así con las directrices del Concilio Vaticano II. Cf. R. Pattée, El catolicismo en los Estados Unidos (EPESA, Madrid 1946) 439-467.

31 Cf. Padre Higgins, [1945], APH s60y02) y NCWC, 1945, APH s16y12.

32 Dice sentirse «cada día más optimista, con tal que un grupo quiera machucarse con ganas», porque, «necesitamos decirle con obras al pueblo, que comprendemos su dolon», Carta a Luis Williamson, 1945, APH s63y64.

33 Cf. Carta a Edwin O'Hara, 1945, APH s70y132 (original en inglés).

34 Este ‘propósito' es el que, desde luego, sentará las bases para su libro El Orden Social Cristiano en los Documentos de la Jerarquía Católica. 
y estar de regreso a principios de enero, para continuar con sus estudios en la Universidad.

El 15 de diciembre viaja a Canadá, hasta principios de enero de $1946^{35}$. En solo tres semanas, visita Québec, Montréal y Ottawa. Toma contacto con l'Union Catholique des Cultivateurs (cooperativas agrícolas canadienses) ${ }^{36}$ y la Facultad de Ciencias Sociales de la Universidad Laval, de Québec, estableciendo diversos $\operatorname{contactos}^{37}$. Estudia a fondo la JOC, la LOC, el movimiento de cooperativas, las uniones crediticias y los sindicatos católicos ${ }^{38}$. En Montréal permanece un tiempo en l'École Sociale Populaire, cuya finalidad era la de «predicary enseñar en Canadá la doctrina social de la Iglesia $\rangle^{39}$, obra que -junto a su fundador- le impactan profundamente. En esa misma ciudad, visita a los Padres Oblatos de María Inmaculada, quienes habían sido recientemente invitados por el Arzobispo de Santiago a realizar una fundación en Chile ${ }^{40}$. El padre Hurtado debió haberles insistido a los Oblatos en la importancia de esta fundación ${ }^{41}$. Invita también a los Padres de San Viator a hacer una fundación en Chile y visita al Gerente de la Editorial Fides ${ }^{42}$.

Después de su paso por Canadá, escribe un interesante documento que titula: «Lo que podría bacerse en Chile»» ${ }^{43}$. De regreso a Washington, pasa por Detroit, Chicago y Milwaukee, el 7 de enero ya se encuentra en Washington, donde permanece hasta fines de mes, continuando con su plan de estudio ${ }^{44}$.

35 Cf. Carta a Mercedes Peña, 1945, APH s65y07.

36 Union Catholique des Cultivateurs, [1945], APH s61y08o.

37 Cf. Carta de Eugène Bussière, 1946, CR1946m05d16.

38 Cf. Sindicatos católicos, [1945], APH s61y08m.

39 Cf. L'École sociale populaire, [1945], APH s61y08j.

40 La primera petición para realizar una fundación en nuestro país había sido hecha por el Arzobispo de Santiago de Chile a la Provincia Oblata de Canadá, el 8 de octubre de 1945 (Codex Historicus OMI).

41 Alberto Hurtado anota: «La ida de los Oblatos sería de gran importancia y que vivieran como en Montréal junto a la JOC», Lo que podría bacerse en Chile, [1946], APH s61y08q.

42 Cf. Carta de Lonis-Philippe Fafard, 1946, CR1946m01d15 y Carta al Director Gerente de Ediciones Fides, 1946, APH s63y27.

43 Lo que podria hacerse en Chile, [1946], APH s61y08q.

44 Cf. Estados Unidos, [1946], APH s16y03; América del Norte y América del Sur, [1946], APH s61y07b; Carta a Elena de Vižcaino, 1947, APH s65y33 y Carta a Mercedes Peña, 1946, APH s65y10. 


\section{Retiro en Baltimore y regreso a Chile}

Inesperadamente, a mediados de enero, el padre Hurtado recibe una carta de su Provincial en Chile, que está aquejado por la falta de personal, pidiéndole que haga lo posible por estar en Chile el 20 de Marzo, para iniciar el año en el Colegio San Ignacio ${ }^{45}$. El 19 de enero, muy afligido, le escribe a Mons. O'Hara disculpándose ante este cambio, pues la beca cubría un año de estudio. Este cambio fue algo imprevisto para el sacerdote chileno ${ }^{46}$. A pesar de esto, le comenta que estos meses le han significado una experiencia sumamente provechosa: conoce mucho mejor los EE. UU., su gente, su vida y su carácter, la vida parroquial, el esfuerzo de los obispos por promover una educación religiosa y el trabajo de las diversas organizaciones que ha podido visitar y conocer. Le cuenta que está preparando algunas conferencias para dar a su regreso, sobre éstos y otros tópicos de América y que ha ordenado sistemáticamente las encíclicas y pastorales sociales. Por último, le dice que espera ir a Nueva York en febrero para estudiar varias instituciones católicas. A los pocos días le responde Mons. O’Hara, lamentando su anticipado regreso a Chile, aunque dice no estar sorprendido por la decisión de sus Superiores ${ }^{47}$.

El 29 de enero comienza sus Ejercicios Espirituales en Baltimore, donde están presentes muy fuertemente los temas existenciales y, por primera vez en su estadía en EE. UU., aparece una cierta crítica al tipo de desarrollo de ese país ${ }^{48}$. Una vez terminados los Ejercicios, pasa unos días en Nueva York, en la casa de los Padres que editan la revista America, tomando contacto nuevamente con obras sociales ${ }^{49}$. Finalmente, la tercera semana de febrero se embarca de regreso a Valparaíso, a bordo del «Illapel», de la Sudamericana de Vapores, donde redacta el retiro de Semana Santa que daría a jóvenes, en abril de $1946^{50}$.

45 Cf. Carta a Edwin O'Hara, 1946, APH s70y133.

46 De hecho, tenía programando con Miguel Covarrubias un viaje rápido a Bélgica, en marzo, para estudiar los sindicatos católicos y la liga de campesinos, cf. Carta de Miguel Covarrubias, 1945, CR1945m12d13 y Carta de Miguel Covarrubias, 1945, CR1945m12d30.

47 Cf. Carta a Edwin O'Hara, 1946, APH s70y133 y Carta de Edwin O'Hara, 1946, CR1946m01d22.

48 Cf. Estados Unidos, [1946], APH s16y03; ¿Cómo vivir la vida?, [1946], APH s52y12; La Samaritana, [1946], APH s30y05; Caná de Galilea, [1946], APH s36y21 y Tres mujeres del Evangelio, [1946], APH s39y16.

49 Carta a Rebeca de Franke, 1946, APH s65y44.

50 Carta a Rebeca de Franke, 1946, APH s65y44. Este retiro a jóvenes se encuentra casi enteramente publicado en S. FERnÁNDEZ (ed.), Un disparo a la eternidad. Retiros espiri- 


\section{Lo que aprendió en el viaje y sus consecuencias para su trabajo social}

\section{Impacto de las instituciones de caridad}

Uno de los propósitos del viaje, tal como se verá, era el de visitar instituciones de caridad, para aplicarlas al Hogar de Cristo. Estas visitas se concentran en las primeras semanas de su estadía en EE. UU. A continuación, se presentan las principales reflexiones de Alberto Hurtado acerca de estas instituciones.

\section{a. Diferencia entre la situación de EE. UU. y la chilena}

A su llegada a Kansas, durante el primer mes, realizó un intenso recorrido por las diversas obras de caridad impulsadas por la Iglesia. Sin embargo, descubre una situación social tan distinta a la chilena, tal como le comenta a una colaboradora del Hogar de Cristo:

«Aquí he tratado de ver las obras similares [al Hogar de Cristo] que he podido, pero no existen. Fui en Kansas City a ver la hospedería para vagos, pero me encontré con un club como el Hotel Victoria, jal menos! En Saint Louis fuí a otra obra similar creada por el famoso Padre Trin, pero es un asilo de ancianos. No hay vagos: ése es el hecho. La gente trabaja y no podrían entender nuestra situación que, cuando uno la ve de lejos, la encuentra aún más deprimente» ${ }^{51}$.

La carta muestra el propósito del padre Hurtado de visitar obras semejantes al Hogar de Cristo. Pero, él mismo constata que al Saint Christopher's Inn solo «llegan los que no tienen donde dormir, vestidos como caballeros ${ }^{52}$. Respecto de los hoteles para pobres del padre Demsey, afirma: "Ocasionalmente van los que no tienen dónde dormir, que son muy pocos en St. Louis». Visita, además, la Parroquia de San Patricio con dos asilos, un orfanotorio, un restaurante, «todo de caridad» ${ }^{53}$. Sin embargo, la constatación sigue siendo la misma: «no hay vagos», y la distancia le hace enfrentar más duramente la realidad «aún más deprimente» que le espera en Chile. Con todo, esto no es impedimento alguno para seguir visitando obras, tomar ideas, aprender lo más posible del modo con que la Iglesia de EE. UU. lleva adelante su labor de caridad.

tuales predicados por el Padre Alberto Hurtado, S.J. (Santiago, 2002) 35-73.

51 Cf. Carta a Mercedes Peña, 1945, APH s65y05.

52 St. Christopher's Inn, [1945], APH s16y09.

53 St. Christopher's Inn, [1945], APH s16y09. 


\section{b. Limpieza y dignidad en las instituciones de caridad}

Alberto Hurtado valora mucho en sus apuntes la preocupación por la limpieza, la belleza y la comodidad material de las instalaciones de las instituciones eclesiales de caridad:

«Fui a un asilo en Kansas City. Precioso, un espejo de limpieza [...]. La casa es una maravilla [...], piezas cómodas, buenas camas» $»^{54}$.

Ahora bien, el valor de la limpieza y la belleza reside en que destaca la dignidad de quienes son acogidos: «Si piden ropa, el Padre les manda comprar ropa nueva, a su medida, para que se sientan bien y no se avergüencen $r^{55}$. Esta preocupación por la dignidad de la persona será un sello del ministerio del padre Hurtado en el Hogar de Cristo. En los testimonios de su trabajo en el Hogar, frecuentemente se destaca la atención por la dignidad de los pobres expresada en el esmero por la ropa adecuada, la calidad de las camas y la limpieza. De hecho, poco antes de morir, les pidió a las colaboradoras del Hogar de Cristo: «Que los detalles para dignificar al pobre sea lo más importantes ${ }^{56}$.

\section{c. Uso de los medios humanos}

Alberto Hurtado se interesa por el modo eficiente con que la Iglesia en EE. UU. organiza y conduce sus obras de caridad. Su mente está totalmente puesta en el Hogar de Cristo, como queda claro en el siguiente manuscrito, que describe su visita al Saint Christopher's Inn:

«Tiene una secretaria bien pagada que hace 100 llamadas telefónicas diarias preguntando si tienen algo que ofrecer para el Hogar de Cristo $[s i]^{57}$. Yo creo que, si me consigo una guía [telefónica] verde, esto va a ser una gran solución. Una persona nada más que al teléfono para mandar a buscar, y un archivo muy bien llevado con direcciones, respuestas, fecha del llamado, etc. $\rangle^{58}$.

54 St. Christopher's Inn, [1945], APH s16y09.

55 St. Christopher's Inn, [1945], APH s16y09.

56 M. Holley, «Diario de la enfermedad y muerte del P. Hurtado», en M. Clavero (ed.), Biografia y testimonios de san Alberto Hurtado (Santiago, 2010) 124. Cf. Proceso Cognicional, Testimonio del Sr. José Antonio Palma: «En esa oportunidad la Madre me dio un vestón de talla mayor que la mía; el Padre se disgustó y dijo que los niños no eran "tonis"》.

57 Este lapsus del manuscrito muestra hasta qué punto está pensando en lo que va a copiar a su regreso a Chile para el funcionamiento del Hogar de Cristo.

58 St. Christopher's Inn, [1945], APH s16y09. 
El padre Hurtado valora la colaboración humana para el desarrollo de una obra como el Hogar de Cristo. También se interesa por la utilización de los medios de comunicación por parte de los norteamericanos para difundir sus obras sociales. En St. Louis, por ejemplo, el apostolado del padre Murphy, quien tenía a su cargo una radio con el Programa del Sagrado Corazón, que todos los días daba una pequeña charla, transmitía el Ángelus, invitaba a la oración y animaba a colaborar en las obras sociales. Son interesantes las impresiones que el padre Hurtado va anotando, mientras describe las obras visitadas:

«El programa del Sagrado Corazón: en discos. Hay más de 100 estaciones que lo tienen. [...]. En realidad que sería un trabajo precioso éste de la radio de gran aliento y en el que no interfiere con la vida parroquial. Numerosas conversiones y abundantes limosnas» ${ }^{59}$.

Cabe señalar que el jesuita chileno tenía familiaridad con la radio en nuestro país ${ }^{60}$. Lo que es novedoso, es la idea de contar con una radio «de gran aliento», es decir, un medio de comunicación estable para la evangelización y la difusión de las obras sociales de la Iglesia. También le atrae la cantidad de publicaciones con que cuentan los católicos de ese país: «Hay unas 300 publicaciones semanales católicas en Estados Unidos» ${ }^{61}$. Lo que le interesa es el modo con que difunden, en esas publicaciones, sus obras de caridad.

\section{d. Organización y responsabilidad de los laicos en la Iglesia}

San Alberto queda muy admirado con la organización de la Iglesia estadounidense y la responsabilidad de sus laicos en las obras de caridad, pues todos sienten que forman parte de ellas, y cooperan:

«Vista de conjunto. Impresiona ver la cantidad de obras que tiene la Iglesia: sus parroquias, asilos, hospitales, casas de ancianos, orfanatorios, casas para caídos... Organización admirable, cooperación de todos, responsabilidad de los laicos inculcada a fondo» ${ }^{62}$.

Asimismo, en otro documento, escrito a comienzos de 1946 con los balances de su viaje, titulado América del Norte y América del Sur, hace un

\footnotetext{
59 St. Christopher's Inn, [1945], APH s16y09.

$60 \mathrm{Al}$ menos desde el año 1942 se tienen registros de Conferencias o Retiros suyos transmitidos por la radio.

${ }^{61}$ NCWC, [1945], APH s15y07.

62 St. Christopher's Inn, [1945], APH s16y09.
} 
esquema con las comparaciones entre las dos culturas eclesiásticas, donde nuevamente vincula los conceptos de «organización»y «cooperación». Refiriéndose a los aspectos más positivos de la Iglesia de Norteamérica destaca: «más serios, más prácticos, más organizados: cooperación» ${ }^{63}$. Así también, en una conferencia que ofrece en Chile sobre su viaje, al poco tiempo de regresar, insiste sobre el mismo punto:

«Organización. Sentido de cooperación. Fruto talvez de ese espíritu de responsabilidad es la magnífica organización norteamericana; porque es en verdad maravilloso el sentido de organización» $»^{64}$.

Es decir, lo que valora de la organización de los laicos norteamericanos es precisamente su hondo sentido de cooperación en las obras que sostiene la Iglesia, lo que no es una idea nueva en él. En esta misma línea, destaca el espíritu de equipo del pueblo y de la Iglesia estadounidense: «El espiritu de equipo significa, en los que lo practican, un inmenso renunciamiento [...] ïDios mío, es canonizable el que trabaja en equipo!!! $)^{65}$.

Otro aspecto que valora a menudo en sus escritos es el sentido de responsabilidad de los norteamericanos por su Iglesia, que realmente sienten como suya, lo que conduce, nuevamente, a una caridad más eficiente. De hecho, llega incluso a advertir que «esta idea de la responsabilidad de los católicos para con su Iglesia es rentable», y continúa, «los hospitales, orfanatorio, Hermanitas de los pobres, refugio para caídos... Sostenidos por los católicos con inmensa generosidad $\aleph^{66}$. Y en otro documento afirma que, en Estados Unidos, «los católicos tienen la "responsabilidad" de su Iglesia iiy la toman en serio!!»" .

\section{e. Sintesis: colaboración bumana y eficiencia en la caridad}

La eficiencia y la organización con que los estadounidenses conducen sus obras de caridad es una idea que atrae mucho a san Alberto Hurtado. En un documento de síntesis, y por lo tanto muy significativo, en que compara el catolicismo norteamericano y el sudamericano, destaca las lecciones para Chile:

\footnotetext{
63 América del Norte y América del Sur, [1946], APH s61y07b.

64 Estados Unidos, [1946], APH s16y03.

65 Caná de Galilea, [1946], APH s36y21.

66 Kansas City, 1945, APH s16y08. El subrayado es propio del manuscrito.

67 Estados Unidos, [1946], APH s16y03.
} 
«Lo que deberíamos aprender: 1) Responsabilidad personal, educar la responsabilidad. 2) Eficiencia: cuidado en lo que se hace. 3) Mayor comprensión de lo humano y más contacto con la vida real. 4) Espíritu de organización» ${ }^{68}$.

Estos elementos están muy relacionados entre sí: responsabilidad, eficiencia, comprensión de lo humano, contacto con la vida real y organización, todos ellos destacan el valor de la realidad humana y de la colaboración humana. Esta insistencia no es nueva en Alberto Hurtado: desde su formación teológica y pedagógica en Lovaina, asimiló la corriente renovadora de la Nouvelle Théologie y, particularmente, de la teología de la creación, que destacan el valor teológico de las realidades terrenas ${ }^{69}$. De hecho, «Una nueva valoración de las realidades terrenas en su propia consistencia es

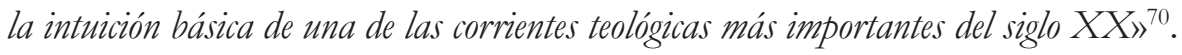
Esta valoración de las realidades terrenas ya le había causado problemas en Chile, en 1942, con un formador del Seminario de Santiago que, en una carta, criticaba al padre Hurtado su modo de conducir la Acción Católica por una «importancia desmedida a la organización, con descuido de los elementos sobrenaturales» y una «confianza excesiva en los medios humanos ${ }^{71}$. A la luz de estas dificultades, Alberto Hurtado debió experimentar una confirmación y un fortalecimiento de su confianza en la acción de Dios por medio de la colaboración humana en su contacto con la Iglesia norteamericana. Alberto Hurtado no opone los medios humanos a los medios divinos, como si hubiese que optar por uno de ellos, sino que integra la colaboración humana en el plan de Dios. De hecho, esta valoración de la colaboración humana será una marca característica en el desarrollo del Hogar de Cristo.

68 América del Norte y América del Sur, [1946], APH s61y07b. Continúa en el mismo documento: «Organización maravillosa, por lo menos si la comparamos con la nuestra. El episcopado nacional y su NCWC... Cada diócesis, cada parroquia, sus escuelas... la vida de cada Parroquia, sus actos religiosos, la colaboración seglar, sus estadísticas, anuarios...».

${ }_{69}$ Para la relación entre el padre Hurtado y la Nouvelle Théologie, cf. F. PArRA, «Teología del Cuerpo Místico, Comunión de los Santos y pensamiento social en San Alberto Hurtado. La influencia de Émile Mersch y Karl Adam», Teología y Vida, L (2009) 797-835. Además, una buena síntesis del espíritu lovaniense -que inspirará la teología conciliar- en G. Philips, Pour un christianisme adulte (París 1963).

70 F. Berríos, «La problemática moderna del trabajo como signo de los tiempos», Teología y Vida, L (2009) 554.

71 La carta de R. Silva está publicada en A. Lavín, El Padre Hurtado, amigo y apóstol de los jóvenes (Santiago 1978) 120-121. La respuesta del padre Hurtado está publicada en Cartas e informes, 105-112. 


\section{Impacto de su actividad académica}

De acuerdo con el plan original del viaje, Alberto Hurtado dedicó gran parte de su tiempo al estudio sistemático de la doctrina social de la Iglesia y de la educación escolar religiosa.

\section{a. Trabajo con los documentos de la Doctrina Social de la Iglesia}

El área más significativa de este período de estudio es la relacionada con la doctrina social de la Iglesia. Tomó clases de Sociología con Raymond McGowan $^{72}$, en la National Catholic Welfare Conference (NCWC). En paralelo a estas clases, comenzó un exhaustivo trabajo de sistematización y organización de los documentos sociales de la Iglesia, tanto papales como episcopales. Así se lo describe a Mons. O’Hara en diciembre:

«He estado trabajando seriamente en las encíclicas y [en las cartas] pastorales para ver, en sus fuentes, el pensamiento social católico como es concebido por la jerarquía. Mi propósito es ordenar los documentos papales (y si es posible los principales documentos episcopales) lidiando con los principales problemas sociológicos. El período debería ser desde León XIII hasta Pío XII» ${ }^{73}$.

$\mathrm{Al}$ mes siguiente, le cuenta que su trabajo con las encíclicas sociales y las cartas pastorales de los obispos ha ido avanzando y que los documentos ya se encuentran organizados «en un orden sistemático» y que, precisamente «la ayuda de la NCWC y de las bibliotecas hicieron posible este trabajo» $7^{74}$. Por supuesto, este trabajo de sistematización, que concluyó en Chile $^{75}$, es la base de su libro El Orden Social Cristiano en los Documentos

72 Si bien no hay registros oficiales de que haya tomado un curso con McGowan, se deduce de sus manuscritos, cf. Estados Unidos, [1946], APH s16y03.

73 Carta a Edwin O'Hara, 1945, APH s70y132 (original en inglés).

74 Carta a Edwin O'Hara, 1946, APH s70y133 (original en inglés). El trabajo con los documentos de la jerarquía católica, estuvo vinculado con sus clases y estudio en la NCWC, no con la Universidad Católica de Washington.

75 En noviembre de 1946, describe su trabajo: «Yo comencé en Norte América, una recopilación de todas las cartas pontificias y episcopales que he podido tener a mano sobre materias sociales, desde León XIII a Pio XII. Tengo el trabajo bastante adelantado, pero no be tenido tiempo de sacar en limpio y de ordenar en forma de material de imprenta lo que he reunido. Habría que hacer algunas traducciones y recopilaciones, y ordenar en forma limpia lo que hay que publicar sobre dichas materias. ¿Se atrevería Ud. a "apechugar" con este trabajo de ordenación?», Carta a Carlos Hurtado, 1946, APH s70y086. 
de la Jerarquía Católica, publicado en dos volúmenes en 1948. De hecho, a un amigo le escribe desde Washington, contándole que se encuentra preparando un libro sobre encíclicas y documentos del Episcopado mundial acerca del problema social, y le confiesa admirar cada día más la valentía y riqueza de la doctrina de la Iglesia ${ }^{76}$. Junto a este trabajo de preparación del libro, su profundización en el pensamiento social católico le servirá de base para una serie de charlas y conferencias que realizará a su regreso en Chile ${ }^{77}$.

Su admiración por la doctrina social de la Iglesia le muestra con claridad absoluta la necesidad de penetrar más y más la valiente doctrina social de la Iglesia, $\mathrm{y}$, como le señala a su amigo, «que, sin eufemismos, la revolución de la justicia social, seamos nosotros los que la llevemos a cabo...» ${ }^{78}$.

Todo este estudio lo realiza «pensando en los problemas que tenemos que enfrentar en Chile» ${ }^{79}$, y consciente que «será cuando tenga que enfrentar las dificultades del trabajo habitual cuando más aprecie lo que he aprendido aqui ${ }^{80}$. Insiste además, en la importancia de ahondar en el Magisterio Social de la Iglesia tal como es concebido por la Jerarquía, pues esto se traducirá, a su modo de ver, en un necesario punto de unión entre los sacerdotes:

«Como usted sabe hay muchas formas de pensamiento sobre las doctrinas sociales en Chile entre nuestros sacerdotes, la única idea que puede darnos unión es la enseñanza jerárquica» ${ }^{81}$.

El texto ilumina la realidad eclesial chilena de la época, con relación a su modo de comprender la doctrina social de la Iglesia.

\footnotetext{
76 Cf. Carta a Hugo Montes del 14 de enero de 1946, en Cartas e informes, 163.

$77 \mathrm{Al}$ mismo O'Hara se lo adelanta: «This work will enable us to give a series of lectures on the encyclicals, and to publish them» (Carta a Edwin O'Hara, 1945, APH s70y132). Algunas de estas conferencias son: Los católicos y el problema social en Estados Unidos, [1946], APH s15y03; Catolicismo en Estados Unidos, [1946], APH s15y04a y Estados Unidos, [1946], APH s16y03.

78 Cartas e informes, 163.

79 Carta a Edwin O'Hara, 1945, APH s70y132 (original en inglés).

80 Carta a Edwin O'Hara, 1946, APH s70y133 (original en inglés).

81 Carta a Edwin O'Hara, 1945, APH s70y132 (original en inglés). La respuesta de O'Hara muestra la comunión de ideas entre ambos: "Certainly you are making good use of your opportunity in Washington to study carefully the social teachings of the Holy Fathers from Leo [XIII] to Pius XII. I think the situation can be of the greatest consequence to Chiles) (Carta del 24 de diciembre de 1945, Archivo de Monseñor Edwin O’Hara).
} 


\section{b. McGowan: aplicación y realización de la doctrina social}

A partir del análisis de los manuscritos, aparece claro que lo que más influye para su trabajo académico en los temas sociales fueron las clases del padre McGowan, Director del Departamento Social de la NCWC, recientemente nombrado como sucesor de Mons. John A. Ryan, el llamado «apóstol de la doctrina Sociali de los Estados Unidos ${ }^{82}$, que había fallecido hacía poco como «héroe obrero», en palabras del propio padre Hurtado ${ }^{83}$. McGowan, junto con Ryan, había publicado en 1921 el libro A catechism of the Social Question, el primero de muchos trabajos en que se aplicaban las enseñanzas de Rerum Novarum a las condiciones propias de los Estados Unidos $^{84}$. Realización práctica que atrajo mucho a Alberto Hurtado, tal como él mismo lo destaca:

«La actitud de la Jerarquía de los Estados Unidos merece señalarse con profunda admiración y respeto, pues, para hacer su pronunciamiento tuvo que atropellar dificultades, quizás mayores que en otros países. A raíz de este plan creó la Jerarquía la sección social de la National Catholic Welfare Conference que desde entonces, gracias sobre todo a Monseñor Ryan, a Monseñor Haas, hoy obispo, y al Padre McGowan, ha realizado una magnífica labor de orientación social: estos sacerdotes y algunos otros que los ayudan, con el concurso de un personal permanente numeroso, se han consagrado a la difusión del pensamiento social de la Iglesia y a intervenir en realizaciones avanzadas» ${ }^{85}$.

La NCWC no solo «difunde el pensamiento», sino que «interviene en realizaciones avanzadas». Este carácter práctico atrae mucho al padre Hurtado.

82 Cf. R. PAтTÉE, El catolicismo en los Estados Unidos (Madrid 1946) 363-381. Pattée afirma que «no sería exagerado decir que a monseñor Ryan se le debe una influencia casi desproporcianada en la adaptación concreta de la doctrina social tradicional católica a las condiciones particulares del país, 363. El propio padre Hurtado - en un documento redactado a su regreso en Chile- dice de Ryan: «Toda su vida la consagró a abrir brecha en el terreno social, a traducir a términos norteamericanos la doctrina de las encíclicas) (Los católicos y el problema social en Estados Unidos, [1946], APH s15y03).

83 NCWC, [1945], APH s15y07.

84 Cf. R. Pattée, El catolicismo en los Estados Unidos (Madrid 1946) 323-328.

85 Los católicos y el problema social en Estados Unidos, [1946], APH s15y03. Esta búsqueda de «producir la sintesis entre nuestras doctrinas y nuestras realidades» está presente en $\mathrm{Al}$ berto Hurtado aun antes de su viaje. Cf. S. Fernández (ed.), La búsqueda de Dios. Conferencias, articulos y discursos pastorales del Padre Alberto Hurtado, S.J. (Santiago, 2005) 112-113. 


\section{c. McGowan: justicia y «caridad social»}

En sus clases con McGowan, profundiza en los conceptos de justicia social y caridad social. Junto a las encíclicas, estudia una serie de «artículos cortos de Monseñor Ryan sobre justicia sociabi ${ }^{86}$ y la tesis del padre William Ferree (Secretario del Departamento de Educación de la NCWC), también sobre Justicia Social, la que cita varias veces en sus escritos ${ }^{87}$. En sus apuntes de clases destaca la idea de que la justicia social requiere necesariamente de un orden social para poder llevarse a cabo, y, más aun, que «la caridad social debiera ser el alma del orden social para establecer la justicia sociali ${ }^{88}$. Acerca de la justicia social, insiste nuevamente en la necesidad de traducir las encíclicas:

«El énfasis en la justicia social hay que ponerlo en la virtud que nos obliga a establecer el orden económico-social-jurídico que nos permitirá traducir las encíclicas en realidad, por el bien común del individuo, grupo, sociedad $\rangle^{89}$.

Acerca de la caridad social, es interesante la constatación que realiza el propio padre Hurtado: "Social charity" (nadie trata del punto)»", porque de hecho, él ya hablaba de «caridad social» antes de su viaje. El concepto aparece por primera vez en sus escritos pocos meses antes de partir al país del Norte, en una conferencia en la Universidad Católica de Santiago, en junio de 1945, lo que además muestra que es un tema que, si bien no es nuevo para él, era bastante reciente ${ }^{91}$. Debió, por ello, sentirse muy alentado porque un estudioso experto en justicia social, de la talla de McGowan, tratara el punto de la caridad social en sus clases, presentándola además como «el alma del orden social para establecer la justicia social» ${ }^{92}$.

86 Congress Industrial Organization, [1945], APH s61y07c.

87 La tesis se la debió recomendar McGowan. El manuscrito de sus apuntes de clases con él señala: «Father Ferree. Thesis, a good thesis on Social Justice» (Padre Higgins, [1945], APH s60y02).

Padre Higgins, [1945], APH s60y02 (original de esta parte del manuscrito en inglés). Padre Higgins, [1945], APH s60y02 (original de esta parte del manuscrito en inglés).

Padre Higgins, [1945], APH s60y02. El manuscrito es sumamante interesante, ya que es posible identificar - a partir del uso de los idiomas, inglés y español- lo que corresponde a apuntes de clases, de las propias reflexiones del jesuita chileno.

91 Cf. La búsqueda de Dios, 112-113.

92 Resuena, en efecto, la idea tantas veces repetida en sus escritos, al hablar de justicia, señala que esta debe estar «coronada por la caridad» (cf. Desfile antorchas, Congreso SSCC, 1944, APH s19y28; Educación de la caridad, [1944], APH s49y17; Educación de la caridad, [1944], APH s51y18b; [Vigilia de Navidad], [1939], APH s54y12 y El deber de la Cari- 
d. Una «idea que es nueva»: la reforma de las instituciones

Lo que resulta novedoso entonces no es tanto el uso de los términos, sino verse confirmado en la «idea que es nueva»: que la justicia social requiere de una reforma social y no únicamente de caridad individual ${ }^{93}$. Para el padre Hurtado, justicia social y caridad social, que están en la base de este nuevo orden social, requieren necesariamente de una reforma social que suponga una reforma no solo individual, sino estructural, tal como se lee en sus anotaciones de clases:

«Una razón para enseñar sociología es la idea, que es nueva: que la reforma social necesita de la reforma de las instituciones, no solo la moral del individuo. Por eso se necesita absolutamente» ${ }^{94}$.

La lectura diacrónica de los escritos del santo muestra un desarrollo en este punto de su pensamiento social: en una primera etapa sostiene que la reforma moral del individuo es capaz de lograr la reforma de la sociedad, luego comienza a valorar cada vez más el cambio estructural: «La moral individual es insuficiente» ${ }^{95}$. Finalmente, sostiene que reforma estructural e individual se necesitan mutuamente: «ambas se complementan» ${ }^{96}$. Nuevamente se encuentra presente el tema de la colaboración humana al plan divino, en este caso, se trata de una colaboración social. Esta lectura diacrónica muestra la relevancia del período de estudio en EE. UU. en la evolución del pensamiento social de Alberto Hurtado, en especial, por influencia de las clases con McGowan y de su estudio sistemático de las encíclicas sociales ${ }^{97}$.

dad, 1944, APH s54y27). La misma idea se repite varias veces en sus libros El Orden Social Cristiano en los Documentos de la Jerarquia Católica y Moral Social.

93 Es el tema de su libro Moral Social, redactado en 1952, y que no alcanzó a publicar. La obra fue publicada años después por P. Miranda, Moral Social. Obra póstuma del Padre Alberto Hurtado, S.J. (Santiago 2004). Ver también P. MirandA, «Preludios del aggiornamento de la moral social en América Latina», Moralia, 31 (Madrid 2008) 159-184.

94 Padre Higgins, [1945], APH s60y02.

95 Cf. S. FERnÁNDEZ, «¿Reformar al individuo o reformar la sociedad? Un punto central en el desarrollo cronológico del pensamiento social de San Alberto Hurtado», Teología y Vida, IL (2008) 514-544. Cf. Reforma de estructuras, [1948], APH s24y07.

96 La síntesis se encuentra en su último libro, Moral Social, 225.

97 Particularmente de Quadragessimo Anno, como él mismo señala en un documento redactado en Baltimore: «Y para reformar la sociedad, dice Quadragessimo Anno: reforma moral y reforma [de las] instituciones» (Caná de Galilea, [1946], APH s36y21). Es muy interesante, a su vez, verificar que esta idea la aplica a diversos 'ámbitos de acción', como la economía, la sociología, incluso también a la formación religiosa, como lo 
Impacto y consecuencias del viaje a los Estados Unidos de 1945 en el ministerio... $\mid 573$

\section{e. Formación del proyecto de la ASICH}

Las obras «de caridad social» que más impactaron al padre Hurtado fueron: The Rural Life, The Rockburst Institute, ambas con sede principal en Kansas, y l'École Sociale Populaire, de Canadá.

The Rural Life, era una obra fundada por Mons. O'Hara para dar educación a los hijos de los campesinos, como medio de reforma social en el mundo rural. Para conocer mejor esta obra, san Alberto viaja a Des Moines (Iowa) para asistir a su Congreso Anual. Queda con mala impresión de su organización:

«Las charlas que dan sus oradores, muy pobres, como muy pobre el nivel de discusiones. Las reuniones en general muy aburridas [...]. Traía grandes esperanzas, pero mi impresión es de una realidad mucho menor ${ }^{98}$.

Impresión general pobre de su organización, de la bilblioteca (solamente en inglés) y de la capacidad de trabajo. Las otras dos, en cambio, merecieron mayores elogios por parte del jesuita chileno.

The Rockburst Institute concentraba el esfuerzo de los jesuitas de Kansas City en el plano sindical y obrero 99 . La estructura de trabajo del Instituto arroja luces acerca del particular interés del padre Hurtado:

«Trabajo del Instituto Rockhurst. A cargo del Padre Friedl. Trabajo en apariencia de poca monta, pero de gran influencia porque especializado: unos 200 jefes industriales y obreros. Ha intervenido en más de 100 conflictos del trabajo. Nació la idea en el Padre Friedl al leer el insistente llamado del Papa a que demos una formación social, que de hecho no damos. Y por eso: $1^{\circ}$ ) Escuela de obreros dirigentes;

señala en otro documento: «En la formación religiosa distinguir: a) la parroquial - hacer un buen cristiano... y cielo! b) la social - la conversión de la sociedad», donde se ve que la idea de aplicar la reforma estructural a la evangelización es una anticipación a la evangelización de la cultura (How to organise corporations, [1945], APH s15y02).

98 Rural Life Conference, [1945], APH s15y09.

99 Las interesantes reflexiones que hace Alberto Hurtado sobre los sindicatos, durante el viaje, que rebasan nuestro tema, podrían desarrollarse más ampliamente sobre la base de los siguientes manuscritos: Los católicos y el problema social en Estados Unidos, [1946], APH s15y03; Diario de viaje a EE. UU. I], 1945, APH s16y01; [Diario de viaje a EE. UU. III], 1945, APH s16y06; Méjico, [1945], APH s29y12; Origen del Sinarquismo, [1945], APH s29y19; JOC, [1945], APH s61y08f; L'École sociale populaire, [1945], APH s61y08j; How to organise corporations, [1945], APH s15y02; Los católicos y el problema social en Estados Unidos, [1946], APH s15y03 y Sindicatos católicos, [1945], APH s61y08m. 
$2^{\circ}$ ) escuela de patrones; $3^{\circ}$ ) preparación en común, después que han recibido la formación social igual - del mismo Padre-, de un contrato de trabajo; $4^{\circ}$ ) preparación en el College de un título en social rescontruction $\rangle^{100}$.

Esta misma formación social y trabajo «en común» entre dirigentes, obreros y patrones, estará presente en la ASICH. Asistió a una clase del P. Friedl en el Instituto y quedó muy bien impresionado: «Los obreros presentes, unos 60, más de la mitad mujeres, seguian con mucho interés y tomaban notas» ${ }^{101}$.

L'École Sociale Populaire, de Montréal. Esta obra había sido fundada por el padre Joseph Archambault S.J., en 1929, con el fin de «predicary enseñar en Canadá la doctrina social de la Iglesia» ${ }^{102}$, y si bien no era una escuela, sin embargo se le había llegado a llamar Universidad por la infuencia ejercida. Alberto Hurtado quedó muy bien impresionado por la obra y personalidad de Archambault, que además era el Presidente de las Semanas Sociales de Canadá, Director del Comité de Obras Católicas y quien había impulsado los sindicatos católicos, abiertos a católicos y no católicos, en ese país ${ }^{103}$. Las anotaciones en su estadía en esta institución revelan un creciente interés por fundar una obra sindical: «En Chile debe haber muchos no sindicados $i y$ allí está nuestro campo.t $\rangle^{104}$. El interés es mutuo: Archambault invita a Hurtado a prolongar su estadía o a regresar antes de su vuelta a Chile, lo que finalmente no ocurre por falta de tiempo ${ }^{105}$.

En resumen, su contacto con estas obras avivan su anhelo de «traducir las encíclicas en realidadi, y de organizar en Chile una obra de reforma de las estructuras, de caridad social. Para esta realización práctica, pensando ya en una «colaboración futura», tomó contacto con la Facultad de Ciencias Sociales de la Universidad Laval, de Québec, quienes llevaban a cabo una obra de acción social y de educación popular. El intercambio epistolar con Eugène Bussière, Secretario de la Universidad, pocos meses después,

\footnotetext{
100 The San Antonio plan, [1945], APH s15y06.

101 The San Antonio plan, [1945], APH s15y06.

102 L'École sociale populaire, [1945], APH s61y08j.

103 Cf. Acción Corporativa, [1945], APH s61y08n; L'École sociale populaire, [1945], APH s61y08j; Semanas Sociales, [1945], APH s61y08k; El comité de las obras católicas, [1945], APH s61y081 y Sindicatos católicos, [1945], APH s61y08m.

104 Sindicatos católicos, [1945], APH s61y08m.

105 Cf. Carta de Joseph Archambault, 1946, CR1946m02d13a: «Cher Père Hurtado, J'ai bien regretté que vous n'ayez pu revenir au Canada. Votre séjour ici a été trop brefi. Cf. también Carta de Joseph Archambault, 1946, CR1946m05d07.
} 
Impacto y consecuencias del viaje a los Estados Unidos de 1945 en el ministerio... $\mid 575$

muestra el desarrollo de los proyectos sociales ${ }^{106}$. De hecho, en octubre, Bussière vuelve a escribirle diciéndole que espera que sus proyectos hayan sido bien acogidos por el Cardenal Caro ${ }^{107}$. Lo que indica que los proyectos están en vías de realización.

Pero, ¿en qué consistían estos proyectos sociales? Es sabido que su mayor obra en este sentido fue la ASICH, pero esta nació recién el 13 de junio de 1947 y solo se consolidó al año siguiente ${ }^{108}$. ¿Qué ocurrió, entonces, entre 1945 y 1947? Algunas cartas y un interesante manuscrito, redactado en EE. UU., en enero de 1946, que titula Lo que podría hacerse en Chile ${ }^{109}$, contienen elementos que permiten reconstruir el desarrollo de sus proyectos sociales. El manuscrito describe las líneas centrales de una Escuela Social, que llama «Ju.So.»:

«Una «Escuela Social», «Ju.So»: Justicia social, en Santiago sería de gran utilidad para ir dando orientación social. Un grupo no muy numeroso, inscripción: gente que no esté muy pescada. ¿Cursos o charlas para los jóvenes? Me inclino a tipo de clases: cortas, con amplia discusión y temario para discutir. Filosofía social = Encíclicas. Realidad nacional. Legislación social nacional y extranjera. Realizaciones y métodos: publicar trabajos en una revista que ya se publica, de modo que difunda. Centralizar en esta Escuela Social los grupos que se interesan por tema social» ${ }^{110}$.

Una vez de vuelta en Chile, en mayo de 1946, le escribe a Rodolfo Valdés invitándolo a «echar a andar los Seminarios de Estudios Sociales de que ya hemos hablado; tú sabes cuánta importancia tienen éstos», lo que muestra que debió haber tenido varias conversaciones al respecto, a pesar que en la misma

106 Las palabras de Bussière son elocuentes: «Je suis heureux d'apprendre que vous poursuivez. toujours la réalisation de vos projets et je suis assuré qu'avec votre grande personnalité, votre foi en Dieu et dans les hommes, vous arriverez au but [...]. La communauté de pensée et d'idéal qui s'est établie dès notre premier contact devrait être, me semble-t-il, un gage de succès dans notre collaboration future», Carta de Eugène Bussière, 1946, CR1946m05d16.

107 Carta de Eugène Bussière, 1946, CR1946m10d22: «J'espère qu'il a bien accueilli vos projets puisque je sais que vous êtes de taille à les mener à bonne fin». Desgraciadamente, no se conservan las cartas originales del padre Hurtado.

108 Cf. Informe del Padre Hurtado, [1952], APH s64y59 y M. Clavero, «Un punto de inflexión en la vida del padre Alberto Hurtado: Itinerario y balance de su viaje a Europa, de 1947», Teología y Vida, XLVI (2005) 311-314.

109 Lo que podría hacerse en Chile, [1946], APH s61y08q.

110 Lo que podría hacerse en Chile, [1946], APH s61y08q. 
carta declare: «no he podido hacer nada, hasta ahora ${ }^{111}$. Al mes siguiente, el 21 de junio de 1946, le escribe a Mons. O’Hara: «Hemos iniciado un Seminario de Estudios Sociales con un grupo de estudiantes universitarios y gente joven, que está avanzando con gran interés ${ }^{112}$. Luego, en noviembre del mismo año, una carta dirigida a Carlos Hurtado describe los avances del proyecto:

«La Central de Servicios Sindicales está funcionando bastante bien, aunque en forma muy incipiente. Estamos en un momento en que más que Central de Servicios Sindicales parece Círculo de Estudios. Pero por algo se comienza [...]. A nuestras reuniones asisten patrones, industriales y obreros. Ahora estamos en plena discusión de la sindicalización Agraria, que ya ha comenzado a ser una realidad en Chile» ${ }^{113}$.

Si bien los nombres cambian, las descripciones de la Escuela Social, «Uu.So.», del Seminario de Estudios Sociales y de la Central de Servicios Sindicales indican que estas distintas organizaciones son el desarrollo de un mismo proyecto. Y, por otra parte, la comparación de los elementos propios de estos sucesivos proyectos con la estructura organizativa de la ASICH muestra la continuidad de ellos con la Acción Sindical Chilena. Luego, estos proyectos son antecedentes de la ASICH, cuyo origen se remontaría, entonces, a su período de estudio en Norteamérica.

\section{f. Su proyecto agrícola}

La correspondencia con Bussière alude a «proyectos sociales», en plural, como el mismo padre Hurtado se lo habría transmitido. Pero, fuera de la ASICH, no se cuenta con datos acerca de algún otro proyecto realizado por Alberto Hurtado a nivel estructural. Sin embargo, a partir de algunas cartas recibidas durante su permanencia en EE. UU. y en los meses siguientes, es posible reconstruir, en parte, otro proyecto social.

Tal como se señaló más arriba, Alberto Hurtado llegó a Kansas con «grandes esperanz̧as» acerca de The Rural Life, pero quedó con una impresión negativa. Naturalmente, su interés era el de proyectar una obra de desarrollo rural en Chile. Rumbo a Washington, se detiene en Sheboygan (Wisconsin) para encontrar al Provincial de los Salvatorianos, el padre Bede Friedrich, y proponerle un proyecto de escuela agrícola en Chile. El 31 de octubre escribe al Superior de la Sociedad de la Preciosa Sangre, pidiéndole

\footnotetext{
111 Carta a Rodolfo Valdés, 1946, APH s70y108.

112 Carta a Edwin O'Hara, 1946, APH s70y134 (original en inglés).

113 Carta a Carlos Hurtado, 1946, APH s70y086.
} 
Impacto y consecuencias del viaje a los Estados Unidos de 1945 en el ministerio... 577

sacerdotes para este proyecto. Lo mismo hace con el Provincial de los Padres de San Viator de Canadá. El 14 de diciembre le escribe al Secretario Ejecutivo de Agricultural Missions, de Nueva York, pidiéndole material de estudio en temas rurales para desarrollar su programa, y el día 15, le cuenta a Mons. O’Hara: «He estado visitando el Ministerio de Agricultura y el Ministerio de Educación para conocer lo que el Gobierno está haciendo en la vida rurabi ${ }^{114}$.

Desgraciadamente, no contamos con las noticias de primera mano acerca de este proyecto, sino solo las respuestas de las distintas congregaciones y organismos a quienes Alberto Hurtado pidió ayuda ${ }^{115}$. A pesar de esto, las cartas recibidas permiten reconstruir, en cierta medida, cuál era su plan. Cabe notar que estas cartas hablan siempre de un proyecto: «your proposed project», «the project in Chile», etc., lo que muestra que se trataba de algo ya estructurado. De acuerdo con la carta que le dirige el P. Bede Friedrich, el 29 de octubre, su proyecto habría consistido en enviar a Chile un grupo de sacerdotes para organizar una Escuela Agrícola bajo el auspicio de la Pontificia Universidad Católica de Chile, ofreciendo cursos a los campesinos con el objetivo de enseñarles cómo manejar sus pequeñas parcelas, en el entendido que bajo el sistema actual se encuentran esclavos de los latifundistas ${ }^{116}$. Por último, tres valiosas cartas de Miguel Covarrubias, desde Chile, aportan más datos sobre este proyecto de Escuela Agrícola. La primera, del 2 de diciembre de 1945, en la cual le cuenta que está «viendo modo de arreglar con Carlos Casanueva [Rector de la UC] las relaciones futuras de la "Sociedad Escuela Agrícola" en que ellos aporten el terreno y regida por un Consejo», y le pide que le envíe un «plano de tipo de escuela agrícola de conjunto y por secciones» ${ }^{117}$. En la segunda, del 13 de diciembre, le dice estar «buscando 50 cuadras para la escuela, cerca de Santiago [...]; si no encuentro haríamos, la escuela en el terreno de la Universidad, que tiene 87,5 hectáreas». Finalmente le insiste en que: «Los Padres vendrían contratados a dirigir una escuela práctica de Agricultura bajo la tuición del fundador o de la Universidad»r ${ }^{118}$. Y una tercera, del 30 de

114 Carta a Edwin O'Hara, 1945, APH s70y132 (original en inglés). Junto con esto, pide donaciones de DDT (un insecticida) «para su institución» (cf. Carta de Jane Hoey, 1946, CR1946m02d13b).

115 Cf. Carta de Bede Friedrich, 1945, CR1945m10d29; Carta de Joseph Marling, 1945, CR1945m11d15; Carta de John Reisner, 1945, CR1945m12d19 y Carta de Louis-Philippe Fafard, 1946, CR1946m01d15.

116 Cf. Carta de Bede Friedrich, 1945, CR1945m10d29.

117 Carta de Miguel Covarrubias, 1945, CR1945m12d02.

118 Carta de Miguel Covarrubias, 1945, CR1945m12d13. 
diciembre, en que le recuerda el carácter técnico y moderno que buscan para la Escuela ${ }^{119}$.

Finalmente, ¿llevó a cabo este plan a su regreso a Chile?, ¿corresponde este proyecto de Escuela Agrícola a la Escuela Granja del Hogar de Cristo en Colina? Las fuentes no permiten contestar con certeza a estas preguntas. Si bien el proyecto de la Escuela Granja de Colina comenzó a concretarse a los pocos meses de su regreso de los EE. UU., en agosto de $1946^{120}$, esta no cuenta ni con profesores universitarios, ni mantiene la colaboración directa con la Universidad Católica como se proyectaba para la Escuela Agrícola. Por otra parte, la Escuela Granja se mantiene ligada al Hogar de Cristo y se enfoca en un trabajo educacional con los niños y adolescentes, mientras que la Escuela Agrícola estaba proyectada para ofrecer educación especializada a campesinos adultos con el fin que aprendieran a explotar mejor sus tierras. Todo esto hace suponer que se trata de proyectos distintos. Si bien no se descarta el influjo que el proyecto agrícola debió tener en la creación de la Escuela Granja del Hogar. Pero no se cuenta con noticias acerca de una Escuela Agrícola impulsada directamente por el padre Hurtado ${ }^{121}$.

\section{g. Educación religiosa}

En otro ámbito, pero siguiendo su plan original de estudio, que se interesaba por la educación religiosa, tomó cursos con Fulton Sheen y W.H. Russell, en la Universidad Católica de Washington. Su interés era profundizar en temas de educación religiosa y filosofía de la religión, que es una de sus tareas en Chile, en el Colegio y en el Hogar Catequístico ${ }^{122}$. Sobre este punto, dice haber aprendido bastante en las clases y en la conversación con

119 Carta de Miguel Covarrubias, 1945, CR1945m12d30. Resulta interesante el carácter técnico que se busca para la formación del campesinado.

120 Carta al P. Archambault del 6 de agosto de 1946: «On vient de me donner une belle ferme de 15 Hectares avec une grande maison tout près de la gare, à 20 minutes par train de Santiago, pour établir là une école industrielle et agricole pour les pauvres adolescents. (...) Je voudrais à tout prix obtenir une communauté religieuse, si possible de prêtres, si non, des frères. Si on pouvait avoir des prêtres canadiens pour la besogne!! Mon Dieu, que ce serait beau! Puis-je vous demander, mon réverend Père de bien vouloir faire les démarches?») (APH s65y01).

121 Miguel Covarrubias estableció finalmente la Fundación "Dolores Valdés de Covarrubias", el año 1953, con el objetivo de «constituir y mantener escuelas de profesores o profesores rurales», Universidad Católica de Chile 1959. Prospecto General, 173-174.

122 Con Russell, al menos, debió haber tenido contacto bastante directo (cf. final del manuscrito: El niño perdido y hallado en el templo, [1945], APH s44y10). 
Impacto y consecuencias del viaje a los Estados Unidos de 1945 en el ministerio... $\mid 579$

varios sacerdotes jóvenes muy interesados en la enseñanza de la Religión ${ }^{123}$. En un artículo, publicado en 1947 en La Revista Católica, el padre Hurtado da cuenta de su interés por la educación religiosa y describe la influencia que su viaje a EE. UU. significó a este respecto:

«En un reciente viaje a los Estados Unidos pude constatar la preocupación por este problema [la enseñanza religiosa] y aproveché la oportunidad que se me ofrecía para asistir a los cursos que dictaba en la Universidad Católica Mons. Fulton U. Sheen sobre filosofía y religión, y el Pbro. W.H. Russell sobre Cristo centro de la enseñanza religiosa. Pude conocer el texto para los cuatro años del «College» por Mons. Cooper, y el que con igual finalidad para los colegios belgas acaban de publicar los Padres Claude, Delepierre, Delcuve, de Marneffe, y Magnée de la Compañía de Jesús. En todos estos libros se echa de ver una franca reacción contra la enseñanza de la apologética como base de la formación religiosa del segundo ciclo de humanidades. Pero lo que más me ha llamado la atención como visión teológica, como esfuerzo maduro de síntesis es el trabajo cuyo principal autor es el P. John Courtney - Murray, S.J.» ${ }^{124}$.

Como en otros ámbitos, Alberto Hurtado buscó adaptar las ideas aprendidas para llevarlas a la práctica. De hecho, el 1 de febrero de 1947, le escribió al padre Delcuve pidiéndole permiso para traducir y adaptar su texto ${ }^{125}$. No se conserva la respuesta, pero debió ser positiva, pues le escribió también al encargado de la Editorial Difusión, Luis Luchía Puig, para publicar el texto de Delcuve, traducido y adaptado, para lo que obtiene una respuesta positiva algunos días después ${ }^{126}$.

\section{Impacto de su retiro en Baltimore: «La materia no basta»}

Se conserva el manuscrito de una importante meditación realizada durante su retiro en Baltimore, que lleva por título: «iCómo vivir la vida h» ${ }^{127}$. Este texto está en estrecha armonía con las meditaciones escritas a bordo del «Illapel», en su viaje de regreso a Chile, y que sirven para conocer el impacto de su retiro en Baltimore, al concluir su intenso viaje por EE. UU. y Canadá.

\footnotetext{
123 Cf. Carta a Edwin O'Hara, 1946, APH s70y133 (original en inglés).

124 «La enseñanza de la Religión en el Segundo Ciclo de Humanidades», La Revista Católica, LXXXII, 932 (1947) 1011-1024.

125 Cf. Carta al Padre Delcuve, 1947, APH s63y26.

126 Cf. Carta a Luis Luchía, 1947, APH s63y25 y Carta de Luis Luchía, 1947, CR1947m02d12.

127 ¿Cómo vivir la vida?, [1946], APH s52y12.
} 
La meditación destaca la desorientación de la sociedad actual, desorientación causada porque vivimos en un mundo «dominado por problemas materiales formidabless. Pero estos problemas materiales no son los de la pobreza, sino los de la abundancia: «Una amargura está oculta en medio de la trama de la vida, debajo de la máscara de aparentes alegrías, y se acude a diversiones ininterrumpidas» ${ }^{128}$. El hombre "no sabe qué logrará después de tanto sacrificio». Se ha ganado la guerra, pero «sin saber por qué». La meditación habla de un mundo organizado para gozar: «del ambiente de placer, de la atracción de los sentidos que punza su carne con vehemencia en un mundo todo organizado para gozan». Todo funciona con un «orden perfecto, al sevicio de la materia». Ante este mundo organizado para gozar y al servicio de la materia, Alberto Hurtado toma una actitud crítica, y se renueva en el valor de la vida de fe, tal como lo anota al final del manuscrito, como conclusión:

«Estas notas escritas en Baltimore en mi primer día de ejercicios. Mi visita a Estados Unidos, me ha confirmado con mayor fuerza que lo esencial es la vida de fe!! ¡Lo que no es esto, nada vale!! ${ }^{129}$.

El padre Hurtado, que había llegado a EE. UU. golpeado por la pobreza, ahora parece estar golpeado por la riqueza. Ante la experiencia del materialismo, realiza una renovación radical de visión de fe, en que la voluntad divina es la suprema realidad:

«Haec est voluntas Dei, sanctificatio vestra. Hambre y sed de justicia, es decir, de santidad. En la jerarquía de amores o valores, lo primero, mi santificación, a velas desplegadas a pesar de vivir en el siglo XX, o mejor, santificándome en el siglo XX y santificando el siglo XX $»^{130}$.

La rectificación es significativa e ilustra bien el giro teológico de aquellos años: el hombre no se santifica «a pesan» del siglo, sino «en el siglo» y «santifica el siglo». Estas ideas están en estrecha relación con el retiro a jóvenes, predicado en la Semana Santa de 1946, retiro cuyas meditaciones fueron escritas a bordo del barco, durante el regreso, y que, por lo tanto, forman parte del viaje. En ellas, expresa la misma crítica a la sociedad de la abundancia:

«Vengo llegando del país más grande del mundo. Así lo decía el segundo grande, Churchill, hablando de Norte América en el hotel más grande del globo, el Waldorff Astoria, allí están los edificios más al-

\footnotetext{
128 ¿Cómo vivir la vida?, [1946], APH s52y12.

129 ¿Cómo vivir la vida?, [1946], APH s52y12.

130 ¿Cómo vivir la vida?, [1946], APH s52y12.
} 
tos, el teatro mayor, Radio City, 7.000 asientos se llena desde las 7 de la mañana hasta la mañana siguiente... todos los records: velocidad y producción... allí está hoy más del 46\% del oro del mundo. Progresos técnicos fantásticos: la muerte se va alejando, la vida prolongando. Millones de automóviles, de frigidaires... y como decía alguien: ¿Y qué? En la ciudad más grande del globo no viviría yo sino es por deber... Y ¿qué impresión de conjunto? Que la materia no basta, que la civilización no llena. ¡Que da demasiado poco y cobra demasiado caro!, ique a precio de esos juguetes se le quita al hombre su verdadera grandeza! $\mathrm{Y}$ al volver de un viaje espléndido para calmar los nervios de tanta agitación en un barco de carga, lento, único pasajero, que me permitía orar, pensar, escribir... reflexionaba: ¿Y es esto todo?» ${ }^{131}$.

En esta meditación se encuentra la misma actitud crítica ante la sociedad de la abundancia que se percibe en el retiro de Baltimore. «La materia no basta» es la idea que Alberto Hurtado repite al concluir su viaje de estudio a EE. UU. Ante el impacto de una sociedad dominada y al servicio de la materia, Alberto Hurtado insiste en la necesidad de la visión de fe. Por eso, la primera meditación de su retiro, redactada aún durante el viaje, la titula "Visión de fe, Visión de eternidad, Visión de voluntad de Dios, Visión de caridad», título totalmente coherente con el contenido de esta y las demás meditaciones.

\section{Conclusiones}

Los datos presentados revelan el profundo significado del viaje a los EE. UU. para el desarrollo del ministerio de san Alberto Hurtado, mucho más que para tomar distancia después de la renuncia a la Acción Católica. Su encuentro con Mons. O’Hara y su contacto con la Iglesia estadounidense lo llevan a tomar conciencia de la importancia del sentido de responsabilidad de los laicos y de su colaboración en la labor de la Iglesia. Sus visitas a las instituciones de caridad lo ayudan a planear el desarrollo concreto del recién creado Hogar de Cristo, poniendo el énfasis en el uso de los medios humanos: organización, eficiencia, limpieza, uso de los medios de comunicación, etc., naturalmente, en colaboración con los medios divinos. Su contacto con McGowan, la NCWC, y algunas instituciones de caridad social confirman su esperanza de que es posible aplicar concretamente la doctrina social de la Iglesia. Esto lo estimula a pensar y pro-

131 Visión de fe, Visión de eternidad, Visión de voluntad de Dios, Visión de caridad, [1946], APH s52y14. El texto ha sido reducido, pero se encuentra completo en, Un disparo a la eternidad, 35-36. 
yectar una obra orientada a la reforma estructural, lo que más tarde será la ASICH. Es novedoso constatar que los antecedentes de la Asociación Sindical Chilena se remontan a este período de estudio en Washington. Estos mismos meses de estudio de los documentos sociales de la Iglesia darán origen a dos importantes publicaciones: Humanismo social, publicado en 1947, que es el desarrollo del libro sobre deberes sociales, iniciado en enero de 1945, y El Orden social cristiano en los documentos de la Jerarquía Católica, publicado en 1948 en dos volúmenes.

Se destaca además el valor que el padre Hurtado otorgó al estudio: una obra como el Hogar de Cristo, que nació de una inspiración, posteriormente fue desarrollada sobre la base del estudio serio de instituciones semejantes. Asimismo, su proyecto social de la ASICH se apoya en meses de estudio y trabajo académico. En este tiempo, crece su conciencia de la insuficiencia de las soluciones individuales a los problemas sociales, y, por lo tanto, de la necesidad de la reforma estructural. En todas estas iniciativas, se percibe una cada vez mayor conciencia de la necesidad de valorar positivamente la colaboración humana a la obra de Dios. Esta valoración de las realidades terrenas es uno de los sustratos que preparaba la renovación propuesta por el Concilio Vaticano II.

Tal como se anotó al inicio, el padre Hurtado partió a EE. UU. golpeado por la pobreza, de la cual había tenido una particular experiencia que lo llevó a fundar el Hogar de Cristo. Durante el viaje conoce la situación social de un país desarrollado y, particularmente, en su retiro en Baltimore toma conciencia de los riesgos de la riqueza y la abundancia, y profundiza su «visión de eternidad». Esta experiencia espiritual lo inspira en su ministerio sacerdotal a predicar que «la materia no basta» y la centralidad de «la visión de fe». Se puede decir entonces, que parte su viaje golpeado por la pobreza, y termina golpeado por la riqueza.

Finalmente, cabe destacar que las dos intuiciones que marcarán el ministerio sacerdotal de sus últimos años: el sentido social y el sentido de Dios $^{132}$, las cuales se desarrollarán plenamente en su viaje a Francia de 1947, encuentran sus antecedentes en sus reflexiones en estos meses en EE. UU. De este modo, este viaje de estudios otorga un nuevo impulso al padre Hurtado a orientar todo su trabajo social a la luz de la fe.

132 Cf. S. FERnÁndeZ, «¿Reformar al individuo o reformar la sociedad? Un punto central en el desarrollo cronológico del pensamiento social de San Alberto Hurtado», 532-544. 
Resumen: Este artículo presenta el impacto y las consecuencias del viaje de san Alberto Hurtado a los Estados Unidos en el año 1945. El acceso a nuevos documentos ha permitido iluminar de mejor manera los motivos del viaje: luego de su renuncia a la Acción Católica, es becado por Mons. Edwin O’Hara para ir a estudiar por un año a la Escuela de Trabajo Social de la Universidad Católica de Washington. El viaje le permite, además, tomar contacto con diversas obras sociales de la Iglesia de EE. UU. y de Canadá, profundizar su estudio en la doctrina social de la Iglesia y sus aplicaciones prácticas, y proyectar dos de sus obras sociales más conocidas: el Hogar de Cristo y la ASICH. Finalmente, el contacto con uno de los países más desarrollados del mundo, le inspira en su ministerio sacerdotal a predicar que «la materia no basta» y la centralidad de «la visión de fe».

Palabras clave: San Alberto Hurtado, viaje a Estados Unidos 1945, catolicismo social, doctrina social de la Iglesia, ASICH.

Abstract: This article shows the impact and the consequences of St. Alberto Hurtado's trip to the United States in 1945. Access to new documents has shed further light on the reasons for the trip: after he renounced the Catholic Action, Mons. Edwin O'Hara gives him a scholarship to study at the Catholic University School of Social Work in Washington. The trip also allows him to get involved in several social works of the U.S. and Canadian Church, deepen his study of the Church's social doctrine and its practical applications, and plan two of his best-known social works: Hogar de Cristo and ASICH. Finally, contact with one of the world's most developed countries inspires him in his priestly ministry to preach that «what is material is not enough» and the centrality of the «vision of faith».

Keywords: St. Alberto Hurtado, trip to United States 1945, social Catholicism, the Church's social doctrine, ASICH. 
